\title{
Reversible Single-Crystal-to-Single-Crystal Phase Transition of Chiral Salicylidenephenylethylamine
}

\author{
Akifumi Takanabe ${ }^{1}$, Takuro Katsufuji ${ }^{1}$, Kohei Johmoto ${ }^{2}$, Hidehiro Uekusa ${ }^{2}$, Motoo Shiro ${ }^{3}$, \\ Hideko Koshima $^{3, *}$ and Toru Asahi ${ }^{1,3}$
}

1 Department of Advanced Science and Engineering, Graduate School of Advanced Science and Engineering, Waseda University, 3-4-1 Okubo, Shinjuku-ku, Tokyo 169-8555, Japan; aki23@moegi.waseda.jp (A.T.);

katsuf@waseda.jp (T.K.); tasahi@waseda.jp (T.A.)

2 Department of Chemistry and Materials Science, Graduate School of Science and Engineering, Tokyo Institute of Technology, 2-12-1 Ookayama, Meguro-ku, Tokyo 152-8551, Japan; johmoto@chem.titech.ac.jp (K.J.); uekusa@cms.titech.ac.jp (H.U.)

3 Researh Organization for Nano \& Life Innovation, Waseda University, 513 Wasedatsurumaki-cho, Shinjuku-ku, Tokyo 162-0041, Japan; msshiro@nyc.odn.ne.jp

* Correspondence: hkoshima@aoni.waseda.jp; Tel.: +81-3-5286-8307; Fax.: +81-3-5369-7327

Academic Editor: Sławomir J. Grabowski

Received: 3 December 2016; Accepted: 26 December 2016; Published: 29 December 2016

\begin{abstract}
The chiral crystal of enantiomeric (S)-N-3,5-di-tert-butylsalicylidene-1-phenylethylamine in the enol form [enol-(S)-1] undergoes a reversible single-crystal-to-single-crystal (SCSC) phase transition at $T_{\mathrm{c}} \approx 3{ }^{\circ} \mathrm{C}$ from the room temperature $\alpha$-form in orthorhombic space group $P 2{ }_{1} 2_{1} 2_{1}$ $\left(Z^{\prime}=1\right)$ to the low temperature $\beta$-form in the monoclinic space group $P 2_{1}\left(Z^{\prime}=2\right)$ with a thermal hysteresis of approximately $1.7^{\circ} \mathrm{C}$. A detailed comparison of the crystal structures of the $\alpha$ - and $\beta$-forms revealed that the 5-tert-butyl group of one molecule in the asymmetric unit of the $\beta$-form rotated by ca. $60^{\circ}$, and the dihedral angle between the phenyl and salicyl planes increased slightly in the $\beta$-form crystal. However, the changes in the molecular conformation and packing arrangement are small, which leads to the reversible SCSC phase transition with no destruction of the crystal lattice. The dielectric constant along the $b$-axis was small, probably due to the weak intermolecular interactions in the crystals.
\end{abstract}

Keywords: reversible single-crystal-to-single-crystal phase transition; enantiomeric (S)-salicylidenephenylethylamine; dielectric properties

\section{Introduction}

A single-crystal-to-single-crystal (SCSC) phase transition is defined as a micro-mutual transformation in crystal structure with no destruction of the crystal lattice. A reversible SCSC phase transition can occur when the changes in the molecular conformation and packing arrangement in the crystal are very small at the phase transition, so there are no cracks or breaks in the crystal. Hence, the reversible SCSC phase transition is a fascinating phenomenon because of its potential applications in ferroelectric and switchable dielectric devices [1-3]. Several molecular crystals that undergo temperature-induced reversible SCSC phase transition have been reported [4-10].

Chiral (S)-N-3,5-di-tert-butylsalicylidene-1-phenylethylamine in the enol-form [enol-(S)-1] has a photochromic nature in the crystalline state caused by photoinduced proton transfer [11]. The plate-like enol-(S)-1 crystals bend reversibly upon ultraviolet (UV) irradiation [12]. Recently, we reported the chiroptical and optical anisotropic properties of photomechanical enol-(S)-1 crystals before and under UV irradiation [13]. In the course of this study, we discovered that the chiral enol-(S)-1 (Scheme 1) crystal underwent a reversible SCSC phase transition from the room temperature 
$\alpha$-form to the low-temperature $\beta$ form at approximately $3{ }^{\circ} \mathrm{C}$. This reversible SCSC phase transition is a rare occurrence because it occurs between two enantiomorphic phases, which also mean noncentrosymmetric phases. The properties such as ferroelectricity, piezoelectricity, and second-order optical nonlinearlity are allowed in a noncentrosymmetric structure. Other noncentrosymmetric SCSC transitions have been previously reported [14]. We discuss a possible mechanism for the enantiomorphic SCSC phase transition based on the crystal structure changes between the $\alpha$ - and $\beta$-forms. The temperature dependence of the dielectric constant in the single crystalline state was also measured.

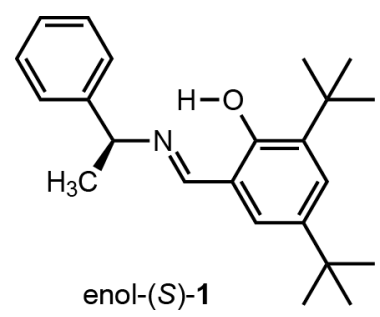

Scheme 1. Enantiomeric (S)-salicylidenephenylethylamine [enol-(S)-1].

\section{Results and Discussion}

The compound enol-(S)-1 was synthesized as reported previously [15]. Single crystals were obtained by slow evaporation of a solution in 2-propanol at room temperature. Differential scanning calorimetry (DSC) of enol-(S)-1 was performed over the temperature range from 10 to $-10{ }^{\circ} \mathrm{C}$ at a rate of $2{ }^{\circ} \mathrm{C} \cdot \mathrm{min}^{-1}$ with cooling initially and then heating (Figure 1). Cooling the crystalline sample of enol-(S)-1 had an exothermic peak at $2.2{ }^{\circ} \mathrm{C}$. The phase transition started at $2.7^{\circ} \mathrm{C}$ and ended at $0.1^{\circ} \mathrm{C}$. Heating the crystalline sample of enol-(S)-1 had an endothermic peak at $3.9^{\circ} \mathrm{C}$. The reverse phase transition began at $3.6^{\circ} \mathrm{C}$ and ended at $4.8^{\circ} \mathrm{C}$. The sharp shapes of these two peaks and the thermal hysteresis of $1.7^{\circ} \mathrm{C}$ reveal a first-order phase transition. The enthalpy at the exothermic and endothermic peaks was -0.69 and $0.67 \mathrm{~kJ} \cdot \mathrm{mol}^{-1}$, respectively. This small thermal hysteresis might be a general feature of SCSC transition because small hysteresis was reported also in the previous papers $[4,7,10]$. DSC curves in wide temperature ranges indicated no existence of additional phase transition (Figure S1).

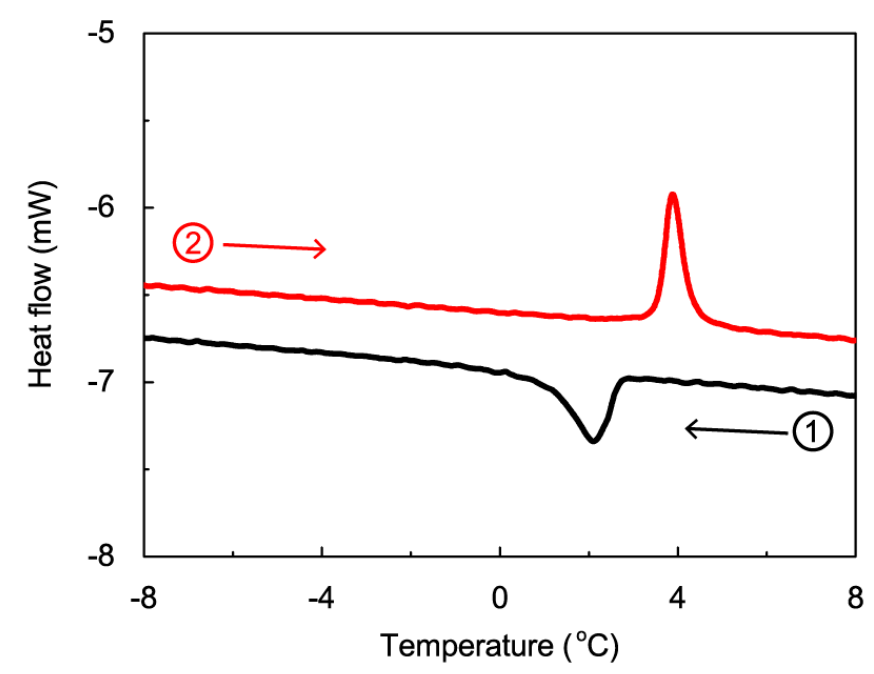

Figure 1. DSC curves of enol-(S)-1 crystal on initial cooling and then heating.

Figure 2 shows the variable-temperature unit cell determination of enol-(S)-1 using a single crystal over the temperature range from -50 to $+50{ }^{\circ} \mathrm{C}$ at $10^{\circ} \mathrm{C}$ intervals with initial heating and then 
cooling. The length of the $a$-axis changed discontinuously between 0 and $10^{\circ} \mathrm{C}$ on heating and cooling; the differences were 0.06 and $0.07 \AA$, respectively (Figure 2a). Angle $\beta$ also changed reversibly from $90^{\circ}$ to $92^{\circ}$ between $0{ }^{\circ} \mathrm{C}$ and $10^{\circ} \mathrm{C}$ on heating and cooling (Figure 2d). The length of the $c$-axis and the volume did not change significantly between $0{ }^{\circ} \mathrm{C}$ and $10^{\circ} \mathrm{C}$ (Figure $2 \mathrm{c}, \mathrm{e}$ ). In contrast, the length of the $b$-axis changed continuously on both heating and cooling (Figure $2 b$ ). The single crystal maintained its transparency without cracking after the heating and cooling cycles, revealing that the phase transition proceeded reversibly via a single crystalline state.

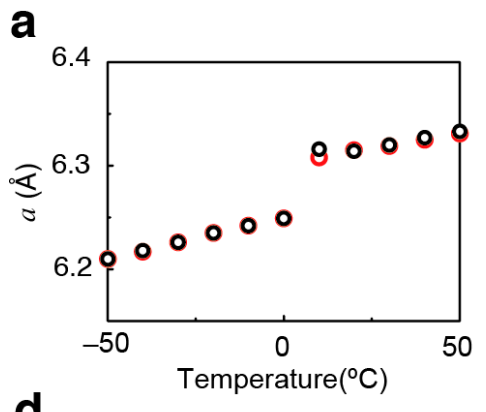

b

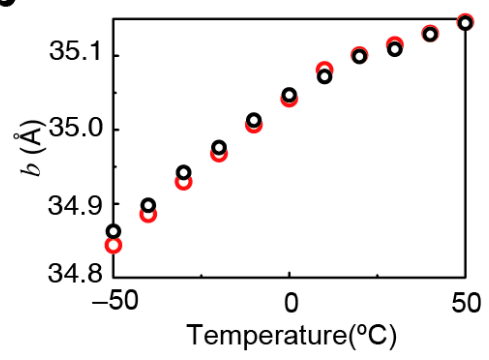

e

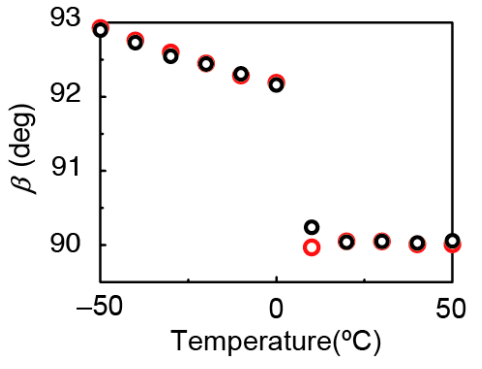

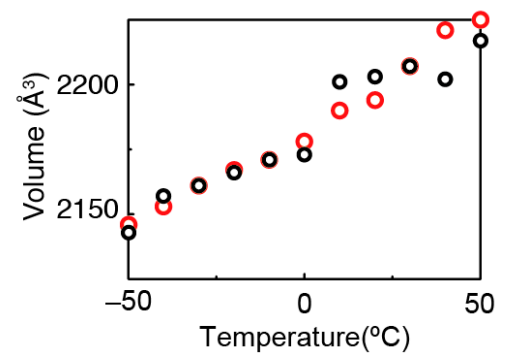

C

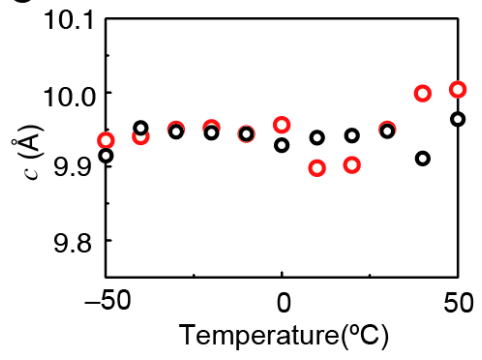

O Cooling

Figure 2. Temperature dependence of the lattice constants of enol-(S)-1 single crystal on initial heating and then cooling; lengths of the (a) $a^{-}$, (b) $b$-, and (c) $c$-axes, (d) angle $\beta$, and (e) volume.

X-ray crystallographic analysis of enol-(S)-1 was performed at $10{ }^{\circ} \mathrm{C}$ and $-50{ }^{\circ} \mathrm{C}$ (Table 1 ). The $\alpha$-form $\left(10^{\circ} \mathrm{C}\right)$ crystallizes in the orthorhombic space group $P 2{ }_{1} 2_{1} 2_{1}$, which is similar to the finding in a previous report [12]. The $\beta$-form $\left(-50^{\circ} \mathrm{C}\right)$ belongs to the monoclinic space group $P 22_{1}$. After the phase transition from the $\alpha$-form to the $\beta$-form, the lengths of the $a$ - and $b$-axes decreased by $-0.09927 \AA$ $(-1.57 \%)$ and $-0.2352 \AA(-0.67 \%)$, respectively, while that of the $c$-axis increased by $+0.04083 \AA$ $(+0.41 \%)$. Overall, the volume decreased by $-42.51 \AA^{3}(-1.94 \%)$. The powder X-ray diffraction (XRD) pattern at room temperature was coincident with the calculated XRD pattern from the single crystal structure of the $\alpha$-form, revealing no existence of additional phase transition (Figure S2).

Table 1. Crystal data for enol-(S)-1 crystals.

\begin{tabular}{ccc}
\hline & $\alpha$-Form & $\beta$-Form \\
\hline Temperature $\left({ }^{\circ} \mathrm{C}\right)$ & 10 & -50 \\
Crystal system & Orthorhombic & Monoclinic \\
Space group & $P 2_{1} 2_{1} 2_{1}$ & $P 2_{1}$ \\
$a(\AA)$ & $6.3058(4)$ & $6.20653(11)$ \\
$b(\AA)$ & $35.071(2)$ & $34.8358(7)$ \\
$c(\AA)$ & $9.8851(6)$ & $9.92593(18)$ \\
$\beta(\mathrm{deg})$ & 90 & $92.7570(10)$ \\
Volume $\left(\AA^{3}\right)$ & $2186.1(2)$ & $2143.59(7)$ \\
$Z$ & 4 & 4 \\
$\rho_{\text {calc }}\left(\mathrm{g} \cdot \mathrm{cm}^{-3}\right)$ & 1.025 & 1.046 \\
$R_{1}[\mathrm{I}>2 \sigma(\mathrm{I})]$ & 0.0681 & 0.0475 \\
Goodness of fit & 1.052 & 1.030 \\
\hline
\end{tabular}


Figure 3 shows the Oak Ridge Thermal Ellipsoid Plot (ORTEP) drawings and molecular conformations of the $\alpha$ - and $\beta$-form crystals. There is one crystallographically independent molecule (A) in the $\alpha$-form crystal (Figure 3a); the 5-tert-butyl group (brown color) is disordered in the 0.217 occupancy. The $\beta$-form crystal consists of two crystallographically independent molecules (B and $\mathrm{C}$ ) in the asymmetric unit (Figure 3b,c). The 5-tert-butyl groups (brown color) of both molecules are disordered in the 0.229 (B) and 0.245 (C) occupancies, respectively.

$$
\alpha \text {-form }
$$

A

a

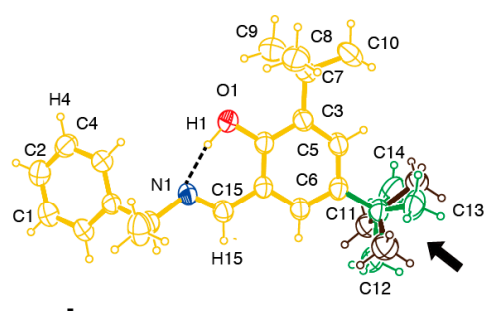

d

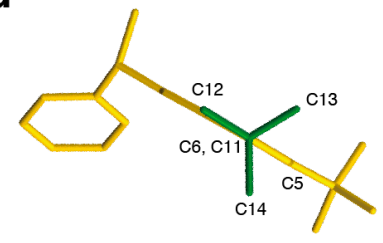

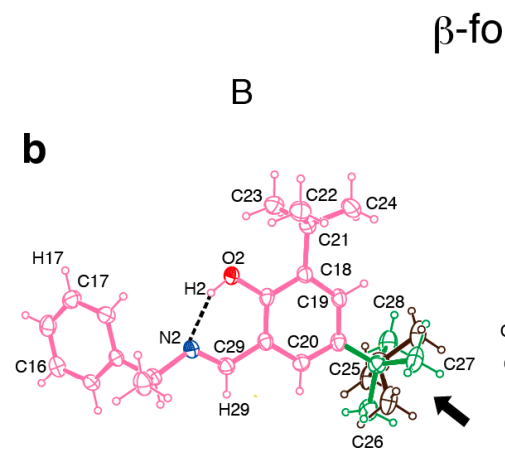

e

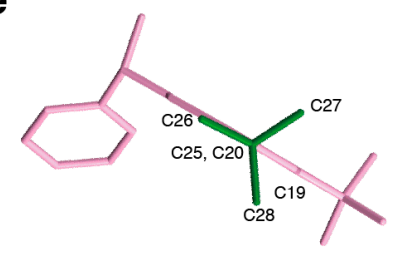

C

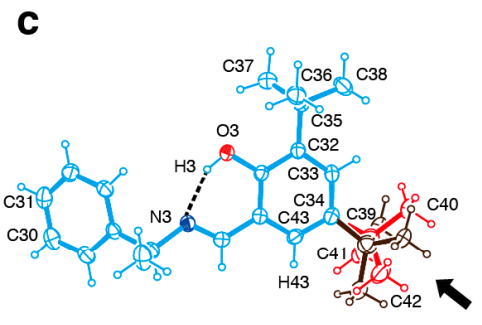

f

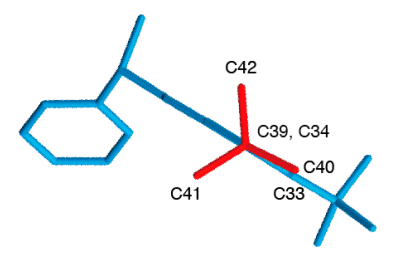

Figure 3. ORTEP drawings $(\mathbf{a}-\mathbf{c})$ at the $25 \%$ probability level, and the molecular conformations $(\mathbf{d}-\mathbf{f})$ of enol-(S)-1 in the $\alpha$ - and $\beta$-form crystals: (a,d) A molecule of $\alpha$-form, (b,e) B, and $(\mathbf{c}, \mathbf{f}) C$ molecules of the $\beta$-form. The 5-tert-butyl groups (brown) are disordered in the 0.217 (A), 0.229 (B), and 0.245 (C) occupancies, respectively. The viewpoints of molecular conformations of the 5-tert-butyl groups are displayed in the ORTEP drawings with black solid arrows. The disordered 5-tert-butyl groups in minor occupancies and all hydrogen atoms in $(\mathbf{d}-\mathbf{f})$ are omitted for clarity.

In molecule $\mathrm{A}$ of the $\alpha$-form, an intramolecular hydrogen bond is formed between the $\mathrm{N}$ atom of the $\mathrm{C}=\mathrm{N}$ Schiff base and the $\mathrm{H}$ atom of the 2-OH group of the salicyl ring (black dotted line in Figure 3a); the $\mathrm{N}-\mathrm{O}$ distance is $2.591 \AA$ and the $\mathrm{N}-\mathrm{H}-\mathrm{O}$ angle is $160.40^{\circ}$. In molecules $\mathrm{B}$ and $\mathrm{C}$ of the $\beta$-form, similar intramolecular hydrogen bonds (black dotted lines in Figure $3 b, c$ ) are formed with $\mathrm{N}-\mathrm{O}$ distances of 2.596 and $2.591 \AA$ and $\mathrm{N}-\mathrm{H}-\mathrm{O}$ angles of $148.67^{\circ}$ and $148.94^{\circ}$, respectively.

The dihedral angle between the phenyl and salicyl plane in molecule A of the $\alpha$-form is $41.06^{\circ}$. The corresponding dihedral angles increase slightly to $46.82^{\circ}$ and $43.97^{\circ}$ in the $\mathrm{B}$ and $\mathrm{C}$ molecules of the $\beta$-form, respectively. The analogous salicylideneaniline crystals can cause a photochromic reaction when the dihedral angle between the phenyl and salicyl planes exceeds $30^{\circ}$ [16]. Therefore, the $\beta$-form crystal should also have a photochromic nature to the trans-keto-form with UV irradiation.

The most significant change in the molecular conformation with the phase transition is that the 5-tert-butyl group (red color) of molecule $\mathrm{C}$ (Figure $3 \mathrm{f}$ ) in the $\beta$-crystal rotates by around $60^{\circ}$ from the original position (green) of molecule A (Figure 3d) in the $\alpha$-crystal, whereas the 5-tert-butyl group (green) of molecule B (Figure 3e) does not rotate. In comparison, the conformations of the 3-tert-butyl groups in molecules $B$ and $C$ do not change drastically from that in molecule A after the phase transition. The torsion angles are shown in Table 2. 
Table 2. Intramolecular hydrogen bonds and molecular conformations for enol-(S)-1 crystals.

\begin{tabular}{cccc}
\hline & $\alpha$-Form & \multicolumn{2}{c}{$\beta$-Form } \\
\cline { 2 - 4 } & Molecule A & Molecule B & Molecule C \\
\hline $\begin{array}{c}\text { Intramolecular hydrogen bond } \\
\text { N-O distance }(\AA)\end{array}$ & & & \\
N-H-O angle (deg) & 2.591 & 2.596 & 2.591 \\
\hline Dihedral angle between & 160.4 & 148.67 & 43.97 \\
phenyl and salicyl plane (deg) & 41.06 & 46.82 & \\
\hline Torsion angle (deg) & & & 126.86 \\
& & & \\
& $(\mathrm{C} 5-\mathrm{C} 6-\mathrm{C} 11-\mathrm{C} 13)$ & $(\mathrm{C} 19-\mathrm{C} 20-\mathrm{C} 25-\mathrm{C} 27)$ & $(\mathrm{C} 33-\mathrm{C} 34-\mathrm{C} 39-\mathrm{C} 42)$ \\
& -59.21 & -55.24 & 6.27 \\
$5-t-\mathrm{Bu}$ group & $(\mathrm{C} 5-\mathrm{C} 6-\mathrm{C} 11-\mathrm{C} 14)$ & $(\mathrm{C} 19-\mathrm{C} 20-\mathrm{C} 25-\mathrm{C} 28)$ & $(\mathrm{C} 33-\mathrm{C} 34-\mathrm{C} 39-\mathrm{C} 40)$ \\
& 178.68 & -175.97 & -115.53 \\
& $(\mathrm{C} 5-\mathrm{C} 6-\mathrm{C} 11-\mathrm{C} 12)$ & $(\mathrm{C} 19-\mathrm{C} 20-\mathrm{C} 25-\mathrm{C} 26)$ & $(\mathrm{C} 33-\mathrm{C} 34-\mathrm{C} 39-\mathrm{C} 41)$ \\
\hline & 123.57 & 121.41 & 125.7 \\
& $(\mathrm{C} 5-\mathrm{C} 3-\mathrm{C} 7-\mathrm{C} 9)$ & $(\mathrm{C} 19-\mathrm{C} 18-\mathrm{C} 21-\mathrm{C} 23)$ & $(\mathrm{C} 33-\mathrm{C} 32-\mathrm{C} 35-\mathrm{C} 37)$ \\
& 3.95 & 1.53 & 6.05 \\
& $(\mathrm{C} 5-\mathrm{C} 3-\mathrm{C} 7-\mathrm{C} 10)$ & $(\mathrm{C} 19-\mathrm{C} 18-\mathrm{C} 21-\mathrm{C} 24)$ & $(\mathrm{C} 33-\mathrm{C} 32-\mathrm{C} 35-\mathrm{C} 38)$ \\
& -115.50 & -117.63 & -112.10 \\
& $(\mathrm{C} 5-\mathrm{C} 3-\mathrm{C} 7-\mathrm{C} 8)$ & $(\mathrm{C} 19-\mathrm{C} 18-\mathrm{C} 21-\mathrm{C} 22)$ & $(\mathrm{C} 33-\mathrm{C} 32-\mathrm{C} 35-\mathrm{C} 36)$ \\
\hline
\end{tabular}

In the $\alpha$-form crystal, four A molecules (yellow) exist in a unit cell (Figure 4a), and a pair of A molecules is arranged in a two-fold helical manner along all axes (Figure $4 a-c$ ) to form a herringbone structure along the $a$-axis (Figure $4 \mathrm{c}$ ). In the $\beta$-form crystal, two B molecules (light pink) and two $C$ molecules (light blue) coexist in a unit cell, and two pairs of $B$ and $C$ molecules are arranged in a two-fold helical manner along the $b$-axis (Figure $4 \mathrm{~d}$ ). The $B$ and $C$ molecules are arranged alternately along the $a$-axis to form a pseudo-herringbone structure (Figure $4 \mathrm{f}$ ).

$\alpha$-form
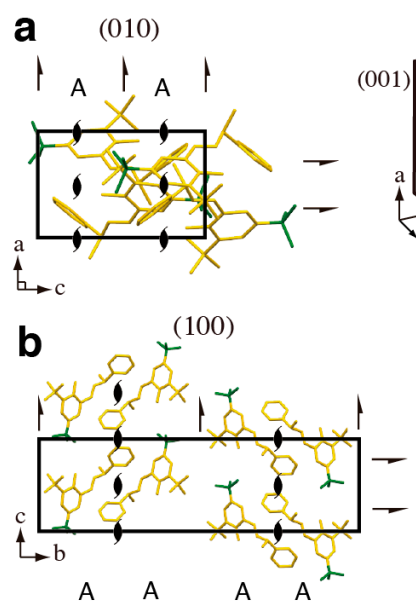

C

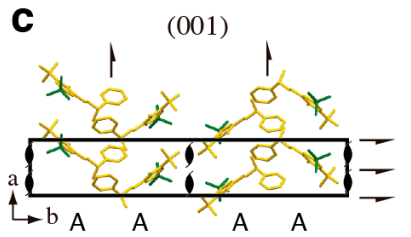

$\beta$-form

d

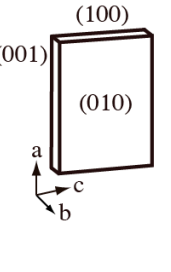

$(010)$

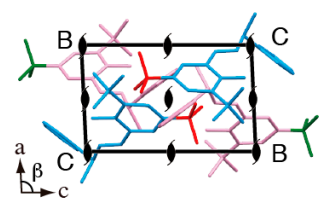

e

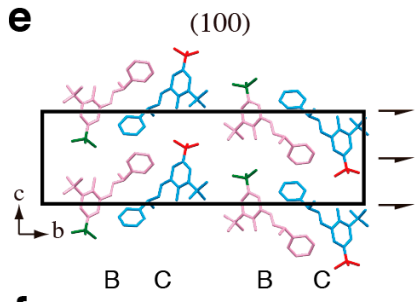

$\mathbf{f}$

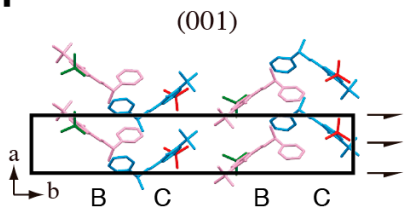

Figure 4. Crystal shape and molecular packings of the (a-c) $\alpha$-form and (d-f) $\beta$-form: $(\mathbf{a}, \mathbf{d})(010)$, $(\mathbf{b}, \mathbf{e})(100)$, and $(\mathbf{c}, \mathbf{f})(001)$ faces. The disordered 5-tert-butyl groups in minor occupancies and all hydrogen atoms are omitted for clarity. 
We discuss a possible mechanism for the reversible SCSC phase transition, based on the changes in the molecular conformation and packing arrangement on the (001) face of the $\alpha$ - and $\beta$-form crystals (Figure 5). The 5-tert-butyl groups of the A molecules of the right column rotate by approximately $60^{\circ}$ (red circular arrow, Figure 5a) at the phase transition point $T_{\mathrm{c}} \approx 3{ }^{\circ} \mathrm{C}$ under cooling; consequently, the A molecules of the right column change into $\mathrm{C}$ molecules (Figure $5 \mathrm{~b}$ ). However, the A molecules of the left column do not rotate at $T_{\mathrm{c}}$ under cooling; consequently, the A molecules of the left column change into B molecules (Figure $5 b$ ). Hence, two crystallographically independent molecules (B and C) are generated by these asymmetrical conformation changes in a pair of A molecules.

As described above, the dihedral angle $41.6^{\circ}$ between the phenyl and salicyl planes in molecule $\mathrm{A}$ increases slightly to $46.82^{\circ}$ and $43.97^{\circ}$ in molecules B and C, respectively. Accordingly, the salicyl rings of the A molecules rotate slightly so that they are almost perpendicular to the (001) face (light blue circular arrow, Figure 5a). The dihedral angle between the salicyl plane and the (001) face increases from $80.94^{\circ}$ (A) to $85.90^{\circ}$ (B) and $81.39^{\circ}$ (C). These conformation changes from $A$ to $B$ and $C$ cause the loss of helical axes along the $a$ - and $c$-axes, which induces the reordering of the packing arrangement from the orthorhombic space group $P 2_{1} 2_{1} 2_{1}$ ( $\alpha$-form) to the monoclinic space group $P 2_{1}$ ( $\beta$-form).
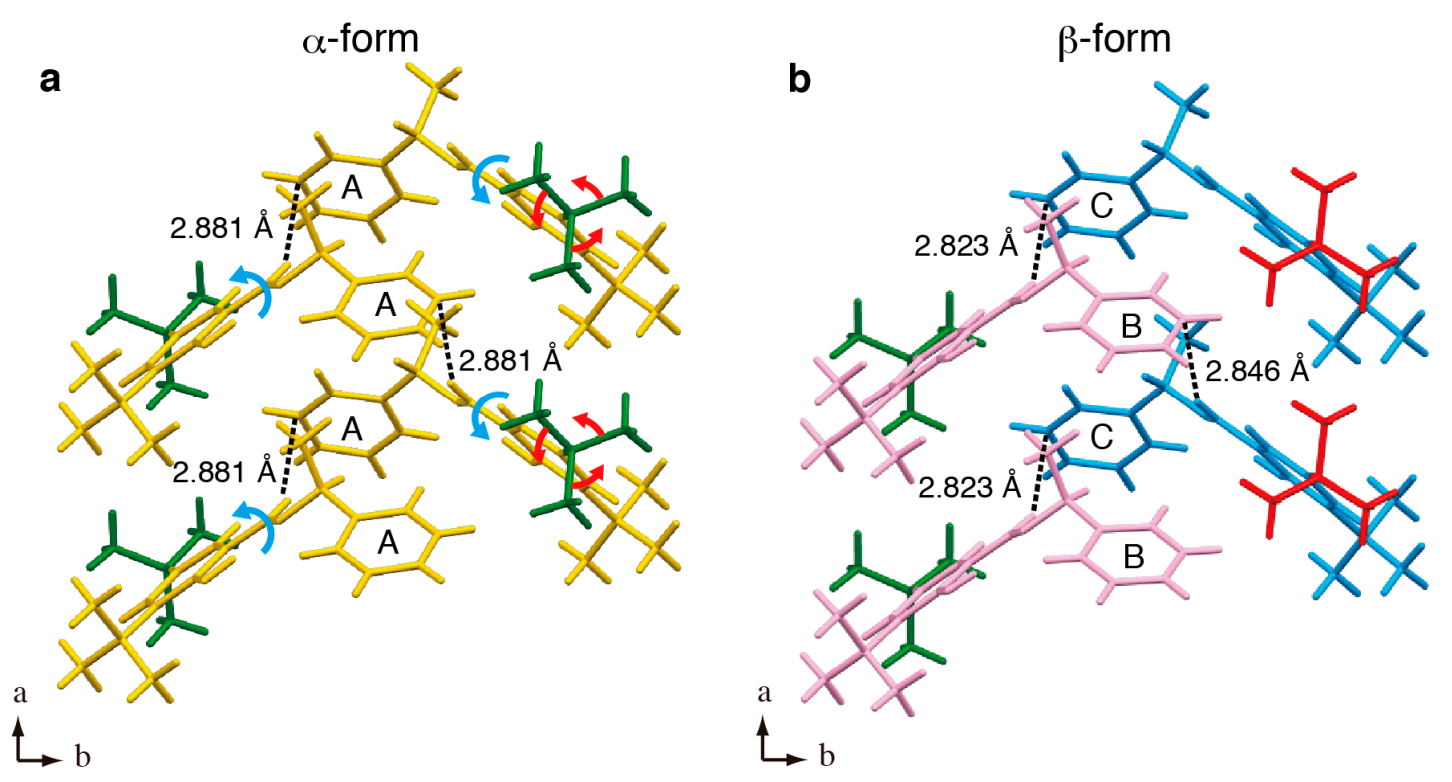

Figure 5. Molecular arrangements with the intermolecular interactions on the (001) face of the (a) $\alpha$ - and (b) $\beta$-form crystals. The A molecules of the left column are converted into the B molecules after the phase transition. The A molecules of the right column are converted into the $\mathrm{C}$ molecules. The disordered 5-tert-butyl groups in minor occupancies are omitted for clarity.

The rotation of the salicyl rings toward the perpendicular to the (001) face leads to closer packing in the direction along the $a$-axis. As a result, the length of the $a$-axis shrinks discontinuously from 6.3058 to $6.2065 \AA$ at the transition point, $\mathrm{T}_{\mathrm{c}}$. Before the phase transition, a weak intermolecular $\mathrm{CH}-\pi$ interaction forms between the Schiff base and the phenyl plane of the A molecules in the $\alpha$-form; the distance is $2.881 \AA$ (black dotted line, Figures $5 \mathrm{a}$ and $6 \mathrm{a}$ ). After the phase transition to the $\beta$-form, the distances of the $\mathrm{CH}-\pi$ interactions between the $\mathrm{B}$ and $\mathrm{C}$ molecules shorten to 2.823 and $2.846 \AA$, respectively (Figures $5 \mathrm{~b}$ and $6 \mathrm{~b}$ ). However, the changes in molecular conformation and the reordering of the packing arrangement are very small, which leads to the reversible SCSC phase transition with no destruction of the crystal lattice. 
$\alpha$-form

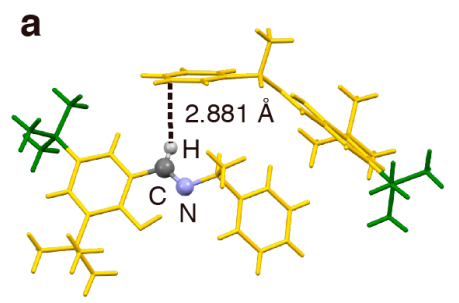

$\beta$-form

b

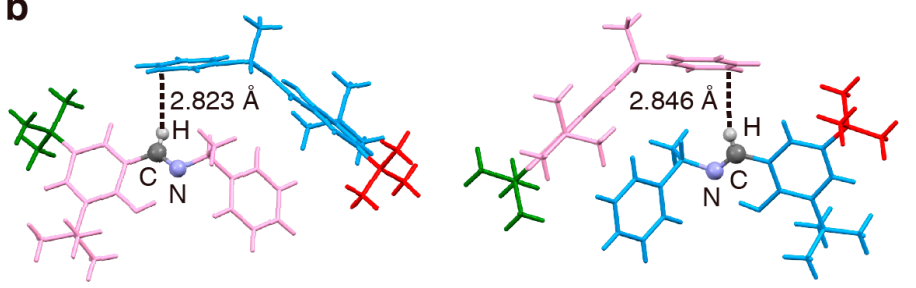

Figure 6. $\mathrm{CH}-\pi$ interaction in the (a) $\alpha$-form and (b) $\beta$-form crystals.

The SCSC phase transition should lead to an anomalous change in the dielectric constant. Millimeter-size square plate $\alpha$-form crystals of enol-(S)-1 were obtained by slow evaporation of the 2-propanol solution at room temperature. The top surfaces were identified as the (010) and (0-10) faces by X-ray crystallography analysis. Hence, the dielectric constant of the depth direction along the $b$-axis was measured. A square plate crystal $(5.4 \times 4.8 \times 0.7 \mathrm{~mm}$ long $\times$ wide $\times$ thick $)$ was fabricated by coating the (010) and (0-10) top surfaces with a silver-based conductive paste, and enameled copper wires were attached to both top surfaces (Figure $7 \mathrm{a}, \mathrm{b}$ ). The temperature dependence of the real part of the dielectric constant $\varepsilon_{\mathrm{r}}$ was measured along the $b$-axis at $1 \mathrm{kHz}$ (see the Experimental Section). The $T-\varepsilon_{\mathrm{r}}$ curve revealed two step-like dielectric anomalies at around 3.4 and $3.9^{\circ} \mathrm{C}$ upon cooling and then heating, respectively (Figure 7c), in agreement with the DSC results (Figure 1). These results also indicate that the transition is a first-order structural phase transition.

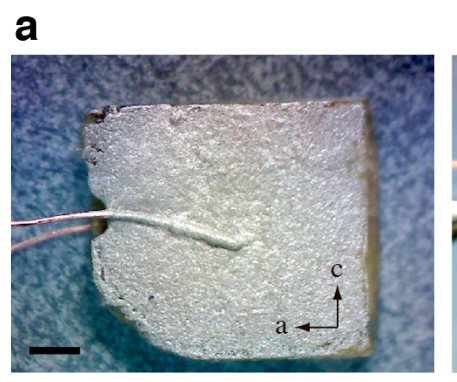

b

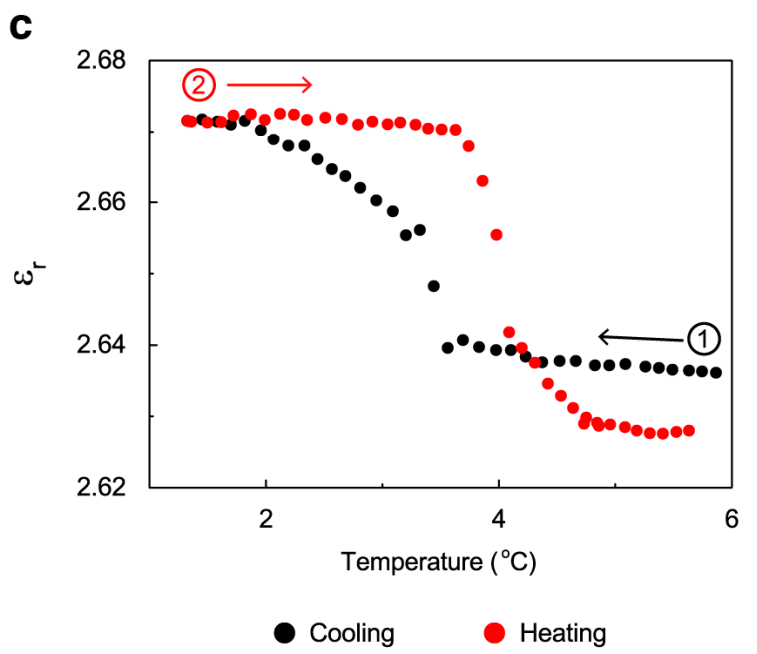

Figure 7. Square plate crystal of enol-(S)-1 with application of silver paste and enameled copper wires: (a) the (010) top face and (b) the (001) side face (the scale bar is $1 \mathrm{~mm}$ ); and (c) temperature dependence of dielectric constant for the enol-(S)-1 crystal along the $b$-axis. The cooling scan was switched into the heating scan at $1.4^{\circ} \mathrm{C}$. 
The dielectric constant $\varepsilon_{\mathrm{r}}$ increased from 2.636 to $2.671(+1.33 \%)$ on cooling from $5.7^{\circ} \mathrm{C}$ to $1.3^{\circ} \mathrm{C}$ (Figure 7c). From the temperature dependence of the lattice constants in Figure 2, the surface area of the (010) face should decrease $(-0.83 \%)$ and the thickness along the $b$-axis should also decrease $(-0.09 \%)$ in the phase transition from the $\alpha$-form $\left(10{ }^{\circ} \mathrm{C}\right)$ to the $\beta$-form $\left(0{ }^{\circ} \mathrm{C}\right)$. The calculated change in the dielectric constant caused by the slight decreases in surface area and depth is $+0.74 \%$ from Equation (1), indicating a slight increase. Hence, the estimated real change in the dielectric constant corrected with the crystal volume shrinkage is $+0.59 \%(=1.33 \%-0.74 \%)$ from Equation (1). This small change in the dielectric constant at the phase transition is derived from the small changes in the molecular conformation and packing arrangement between the $\alpha$ - and $\beta$-form crystals. The maximum $\varepsilon_{\mathrm{r}}$ value (2.67) of the $\beta$-form crystal of enol-(S)-1 along the $b$-axis at $1.5^{\circ} \mathrm{C}$ is similar to that (2.7) of benzyl at $-189^{\circ} \mathrm{C}$ [17] but is lower than those reported for ferroelectric organic crystals [1]. As shown in the packing diagrams (Figures 4 and 5), the intermolecular interactions in both the $\alpha$ - and the $\beta$-form crystals are the van der Waals force and $\mathrm{CH}-\pi$ interactions alone. Such weak intermolecular interactions might have induced the small dielectric constant $\varepsilon_{\mathrm{r}}$. In fact, a large $\varepsilon_{\mathrm{r}}$ value (11) at room temperature has been reported for the croconic acid crystal, in which strong hydrogen-bonded sheets are formed [18].

\section{Experimental Section}

\subsection{Materials}

The compound enol-(S)-1 was synthesized according to the literature procedure [14]. Single crystals were obtained by slow evaporation of the solution in 2-propanol at room temperature within several days. For X-ray crystallographic analysis and dielectric measurements, several single crystals were put into paraffin oil to wash them and were dried. Remaining crystals were used for DSC.

\subsection{Differential Scanning Calorimetry}

DSC runs of enol-(S)-1 crystals (6.58 mg) were recorded using a DSC8500 (PerkinElmer, Norwalk, $\mathrm{CT}$, USA) in the temperature range from $10{ }^{\circ} \mathrm{C}$ to $-10{ }^{\circ} \mathrm{C}$ with a rate of $2{ }^{\circ} \mathrm{C} \cdot \mathrm{min}^{-1}$ on cooling and heating under nitrogen at atmospheric pressure in aluminum crucibles with covers.

\subsection{Crystallography}

$\alpha$-form: Single-crystal X-ray diffraction data were collected at $10{ }^{\circ} \mathrm{C}$ with R-AXIS RAPID II (Rigaku, Tokyo, Japan) using $\mathrm{Cu} \mathrm{K} \alpha$ radiation $(\lambda=1.54186 \AA$ ). The integrated and scaled data were empirically corrected for absorption effects with ABSCOR (Rigaku, Tokyo, Japan) [19]. The initial structures were solved by direct methods with SHELXT 2014 (Göttingen, Germany) [20] and refined on $\mathrm{F}_{0}{ }^{2}$ with SHELXL 2016 (Göttingen, Germany) [21]. With the exception of the disordered C atoms of the tert-butyl group in minor occupancies, the non- $\mathrm{H}$ atoms were refined anisotropically, and all of the $\mathrm{H}$ atoms were obtained geometrically and included in the calculations using the riding atom model.

$\beta$-form: Single-crystal X-ray diffraction data were collected at $-50{ }^{\circ} \mathrm{C}$ with R-AXIS RAPID II (Rigaku) using $\mathrm{Cu} \mathrm{K} \alpha$ radiation $(\lambda=1.54186 \AA)$. The integrated and scaled data were empirically corrected for absorption effects with NUMABS (Rigaku, Tokyo, Japan) [22]. The initial structures were solved by direct methods with SHELXS 97 (Göttingen, Germany) [23] and refined on $\mathrm{F}_{0}{ }^{2}$ with SHELXL 97 (Göttingen, Germany) [23]. With the exception of the disordered tertiary C atoms of the tert-butyl group, the non- $\mathrm{H}$ atoms were refined anisotropically, and all of the $\mathrm{H}$ atoms were obtained geometrically and included in the calculations using the riding atom model. 


\subsection{Dielectric Measurements}

The dielectric constant $\varepsilon_{\mathrm{r}}$ is defined by the equation below:

$$
\varepsilon_{r}=\frac{C d}{\varepsilon_{0} \mathrm{~A}}
$$

where $C$ is the capacitance, in farads; $A$ is the area of a crystal surface, in square meters; $\varepsilon_{0}$ is the electric constant $\left(\varepsilon_{0} \approx 8.854 \times 10^{-12} \mathrm{Fm}^{-1}\right)$; and $d$ is the thickness of plate crystal, in meters. The square plate crystal was fabricated by application of silver-based conductive paste on the (010) and $(0-10)$ top surfaces. The (010) area and the thickness of the crystal were measured by a digital high-speed microscope (VHX-5000; Keyence, Itaska, IL, USA). Capacitance was measured using with a capacitance bridge (1 kHz, AH 2550A; Andeen-Hagerling, Solon, OH, USA).

\section{Conclusions}

The chiral crystal of enantiomeric (S)-salicylidenephenylethylamine enol-(S)-1 undergoes a reversible SCSC phase transition at $T_{\mathrm{C}} \approx 3^{\circ} \mathrm{C}$ from the room temperature $\alpha$-form in orthorhombic space group $P 2_{1} 2_{1} 2_{1}$ to the low temperature $\beta$-form in monoclinic space group $P 2_{1}$ with a thermal hysteresis of around $1.7^{\circ} \mathrm{C}$. The most significant conformation change is the approximately $60^{\circ}$ rotation of the 5-tert-butyl group of one molecule in the asymmetric unit of the $\beta$-form. The small changes in the molecular conformation and packing arrangement lead to the reversible SCSC transformation with no destruction of the crystal lattice. The dielectric constant along the $b$-axis is small, probably due to the weak intermolecular interactions.

Supplementary Materials: Supporting results (DSC and XRD) and CIF files (CCDC 1518678, 1518679) are available online at www.mdpi.com/2073-4352/7/1/7/s1. Figure S1: DSC curves of the enol-(S)-1 crystal over the temperature range from (a) -50 to $+50{ }^{\circ} \mathrm{C}$ and (b) -10 to $+110^{\circ} \mathrm{C}$ on initial heating and then cooling; Figure S2: $\mathrm{X}$-ray diffraction (XRD) patterns of the enol-(S)-1 crystal: powder XRD pattern measured at room temperature (black line) and calculated XRD pattern from the single crystal structure of the $\alpha$-form (red line).

Acknowledgments: This work was supported by the JSPS Scientific Research in the Challenging Exploratory Research, and the grant-in-aid from Mitsubishi Materials Corporation (Tokyo, Japan). We acknowledge Hiroaki Ikeda at Waseda University for his useful suggestions. Akifumi Takanabe acknowledges the Leading Graduate Program in Science and Engineering, Waseda University from MEXT, Japan.

Author Contributions: Collection and assembly of data were conducted by Akifumi Takanabe. The draft of the paper was written by Akifumi Takanabe and Hideko Koshima. Takuro Katsufuji supported the dielectric constant measurement. The crystal structures were analyzed by Motoo Shiro, Kohei Johmoto, and Hidehiro Uekusa. Interpretation of data was conducted by Akifumi Takanabe, Hideko Koshima, and Toru Asahi. All authors have given approval to the final version of the paper.

Conflicts of Interest: The authors declare no conflict of interest.

\section{References}

1. Horiuchi, S.; Tokura, Y. Organic ferroelectrics. Nat. Mater. 2008, 7, 357-366. [CrossRef] [PubMed]

2. Yao, Z.S.; Yamamoto, K.; Cai, H.L.; Takahashi, K.; Sato, O. Above Room Temperature Organic Ferroelectrics: Diprotonated 1,4-Diazabicyclo[2.2.2] octane Shifts between Two 2-Chlorobenzoates. J. Am. Chem. Soc. 2016, 138, 12005-12008. [CrossRef] [PubMed]

3. Tang, Y.Z.; Gu, Z.F.; Xiong, J.B.; Gao, J.X.; Liu, Y.; Wang, B.; Tan, Y.H.; Xu, Q. Unusual Sequential Reversible Phase Transitions Containing Switchable Dielectric Behaviors in Cyclopentyl Ammonium 18-Crown-6 Perchlorate. Chem. Mater. 2016, 28, 4476-4482. [CrossRef]

4. Kaftory, M.; Botoshansky, M.; Kapon, M.; Shteiman, V. Irreversible single-crystal to polycrystal and reversible single-crystal to single-crystal phase transformations in cyanurates. Acta Crystallogr. Sect. B Struct. Sci. 2001, 57, 791-799. [CrossRef] [PubMed]

5. Fernandes, M.A.; Levendis, D.C.; Schoening, F.R.L. A new polymorph of ortho-ethoxy-trans-cinnamic acid: Single-to-single-crystal phase transformation and mechanism. Acta Crystallogr. Sect. B Struct. Sci. 2004, 60, 300-314. [CrossRef] [PubMed] 
6. Takahashi, H.; Ito, Y. Low-temperature-induced reversible single-crystal-to-single-crystal phase transition of 3,4-dichloro-2' $4^{\prime}, 6^{\prime}$-triethylbenzophenone. CrystEngComm 2010, 12, 1628-1634. [CrossRef]

7. Schmidt, A.; Kababya, S.; Appel, M.; Khatib, S.; Botoshansky, M.; Eichen, Y. Measuring the Temperature Width of a First-Order Single Crystal to Single Crystal Phase Transition Using Solid-State NMR: Application to the Polymorphism of 2-(2,4-Dinitrobenzyl)-3-methylpyridine. J. Am. Chem. Soc. 1999, 121, 11291-11299. [CrossRef]

8. Das, D.; Engel, E.; Barbour, L.J. Reversible single-crystal to single-crystal polymorphic phase transformation of an organic crystal. Chem. Commun. 2010, 46, 1676-1678. [CrossRef] [PubMed]

9. Girard, J.; Fromm, K. Single crystal to single crystal polymorphic phase transition of a silver nitrate 24-crown-8 complex and its pseudo-polymorphism. CrystEngComm 2012, 14, 6487-6491. [CrossRef]

10. Pal, R.; Reddy, M.B.M.; Dinesh, B.; Balaram, P.; Row, T.N.G. Temperature-Induced Reversible First-Order Single Crystal to Single Crystal Phase Transition in Boc- $\gamma^{4}(R)$ Val-Val-OH: Interplay of Enthalpy and Entropy. J. Phys. Chem. A 2014, 118, 9568-9574. [CrossRef] [PubMed]

11. Kawato, T.; Koyama, H.; Kanatomi, H.; Shigemizu, H. Difference in the Rate of Photo-induced Unimolecular Motion of Chiral Salicylideneamines in the Chiral Crystal Environments. Chem. Lett. 1997, 26, 401-402. [CrossRef]

12. Koshima, H.; Matsuo, R.; Matsudomi, M.; Uemura, Y.; Shiro, M. Light-Driven Bending Crystals of Salicylidenephenylethylamines in Enantiomeric and Racemate Forms. Cryst. Growth Des. 2013, 13, 4330-4337. [CrossRef]

13. Takanabe, A.; Tanaka, M.; Johmoto, K.; Uekusa, H.; Mori, T.; Koshima, H.; Asahi, T. Optical Activity and Optical Anisotropy in Photomechanical Crystals of Chiral Salicylidenephenylethylamines. J. Am. Chem. Soc. 2016, 45, 15066-15077. [CrossRef] [PubMed]

14. Centore, R.; Jazbinsek, M.; Tuzi, A.; Roviello, A.; Capobianco, A.; Peluso, A. A series of compounds forming polar crystals and showing single-crystal-to-single-crystal transitions between polar phases. CrystEngComm 2012, 14, 2645-2653. [CrossRef]

15. Smith, H.E.; Cook, S.L.; Warren, M.E., Jr. Optically Active Amines. II. The Optical Rotatory Dispersion Curves of the $N$-Benzylidene and Substituted N-Benzylidene Derivatives of Some Open-Chain Primary Amines. J. Org. Chem. 1964, 29, 2265-2272. [CrossRef]

16. Johmoto, K.; Ishida, T.; Sekine, A.; Uekusa, H.; Ohashi, Y. Relation between photochromic properties and molecular structures in salicylideneaniline crystals. Acta Crystallogr. Sect. B Struct. Sci. 2012, 68, 297-304. [CrossRef] [PubMed]

17. Almeida, A.; Dos Santos, M.L.; Chaves, M.R.; Amaral, M.H.; Tolédano, J.C.; Périgaud, A.; Savary, H. Pyroelectric effect in benzil. Ferroelectrics 1988, 79, 253-256. [CrossRef]

18. Horiuchi, S.; Tokunaga, Y.; Giovannetti, G.; Picozzi, S.; Itoh, H.; Shimano, R.; Kumai, R.; Tokura, Y. Above-room-temperature ferroelectricity in a single-component molecular crystal. Nature 2010, 463, 789-792. [CrossRef] [PubMed]

19. Rigaku. ABSCOR; Rigaku Corporation: Tokyo, Japan, 1995.

20. Sheldrick, G.M. SHELXT-Integrated space-group and crystal-structure determination. Acta Crystallogr. Sect. A Found. Adv. 2015, 71, 3-8. [CrossRef] [PubMed]

21. Sheldrick, G.M. Crystal Structure Refinement with SHELXL. Acta Crystallogr. Sect. C Struct. Chem. 2015, 71, 3-8. [CrossRef] [PubMed]

22. Rigaku. NUMABS; Rigaku Corporation: Tokyo, Japan, 1999.

23. Sheldrick, G.M. A Short History of SHELX. Acta Crystallogr. Sect. A Found. Adv. 2008, 64, 112-122. [CrossRef] [PubMed]

(C) 2016 by the authors; licensee MDPI, Basel, Switzerland. This article is an open access article distributed under the terms and conditions of the Creative Commons Attribution (CC-BY) license (http://creativecommons.org/licenses/by/4.0/). 